Point of View

\title{
Patent ductus arteriosus management: Dilemmas for neonatologists in developing nations
}

\author{
*Baljeet Maini ${ }^{1}$
}

Sri Lanka Journal of Child Health, 2022; 51(1): 134-138

DOI: http://dx.doi.org/10.4038/sljch.v51i1.10021

(Keywords: Preterm neonate, Patent ductus arteriosus, Developing nations)

\section{Introduction}

Patent ductus arteriosus (PDA) is a frequently diagnosed entity in preterm babies. Incidence of PDA increases as the gestational age at birth decreases $^{1}$. It has been implicated as a contributor to many neonatal morbidities associated with pulmonary hyper-perfusion (pulmonary haemorrhage, chronic lung disease) or systemic hypo-perfusion (necrotising enterocolitis, acute renal failure $)^{2}$. During the last few decades, echocardiography (echo) and functional sonography have revolutionized neonatal care. Managing PDA using echo is the current standard of care ${ }^{3}$. Biochemical markers of cardiac origin are also being evaluated ${ }^{4}$ Cyclooxygenase inhibitors indomethacin and ibuprofen have been in use for medical closure of PDA ${ }^{5,6}$. Lately, management of PDA has become largely conservative, focusing on treating only the haemodynamically significant shunts and questions such as when and how to manage PDA, are now being re-addressed in the Western countries ${ }^{3,7}$. There is a gross lack of echo facilities in the majority of neonatal intensive care units (NICUs) in developing nations. This article discusses the current understanding and the dilemmas of management of PDAs in the resource poor environment of developing nations.

\section{Current understanding of PDA treatment $P D A$ as a cause of morbidity}

Because neonatal morbidities like necrotising enterocolitis (NEC) and chronic lung disease (CLD) are multi-factorial, how much PDAs actually contribute to their causation is unclear. These morbidities are also independently associated with

${ }^{1}$ Professor of Paediatrics, Teerthankar Mahaveer Medical College and Research Centre, Moradabad, India

*Correspondence: mainibaljeet@gmail.com

https//orcid.org/ 0000-0002-1265-8534

The author declares that there are no conflicts of interest

Personal funding was used for the project.

Open Access Article published under the Creative

Commons Attribution CC-BY (c) (i) License prematurity so that association with PDA is mostly coincidental and not causal ${ }^{3}$. Although short-term outcomes like intraventricular haemorrhage (IVH) were seen to be reduced with prophylactic 'any PDA' closure using indomethacin, there was no marked difference in overall morbidity and mortality. Moreover, no marked difference was noted in neuro-developmental outcome at 18 months, corrected for age, in treated and untreated survivors ${ }^{8}$. With continuously improving management of respiratory morbidities and other issues of preterm babies, the profile of NICU environment is very different now to what it was 3 to 4 decades back. In older studies, the concept of haemodynamically significant PDA was not in usage. Thus, the results of older studies (which included all PDAs) are not comparable to studies on PDAs in today's neonatal management. This casts doubt on the practice of treating 'all PDAs' and exposing preterm neonates to the risks associated with medical or surgical management ${ }^{9}$. Thus, today, it is not right to blame PDA only, for all the morbidity caused by it.

\section{Spontaneous closure of PDA}

In an observational study on the course of untreated PDAs, more than $90 \%$ of healthy preterm (28 to 30 weeks gestation) babies were observed to have spontaneous closure by the time of discharge ${ }^{10}$. In another study, around $75 \%$ of babies below 28 weeks gestation $(<1000 \mathrm{~g})$, had spontaneous closure by the first birthday but with some symptoms associated with an open duct ${ }^{11}$. These studies signify that we do not need to treat all PDAs. This approach will definitely save a lot of babies from unwanted side effects of the currently approved medical armamentarium for PDA closure.

\section{Whom to treat}

As discussed above, many cases of PDA close by themselves and there is hardly any long-term benefit for prophylactically treated babies. Thus, in the last 2 decades, due to the use of echo, the term 'Haemodynamically-significant PDA' ('HsPDA') has come into use for PDA management, focusing on treating only a few selected babies. In advanced centres, neonatologist-performed echo (NPE) is now an established practice. The definition of HsPDA 
takes into account various echo parameters like duct size, pulsatility and direction of shunt flow, left atrial/aortic root ratio and diastolic flow direction in the descending aorta ${ }^{12}$. Still there is no consensus on a single definition for HsPDA. There is concern about various limitations of echo parameters e.g. size of duct as a criterion in the definition of $\mathrm{HsPDA}^{7}$. McNamara PJ, et l $^{3}$ have suggested that a single duct size cannot be significant for all babies and that a measurable shunt flow magnitude may be better suited for PDA severity assessment. There is a paucity of such studies from the developing nations because of a lack of echo facilities. The question of whom to treat may be easy to answer only in limited advanced centres. In developing economies most of the NICUs are without echo facilities and thus the issue of patient selection is very difficult to resolve.

\section{When to treat}

Conventionally, it has been the practice to treat all suspected or clinically evident PDAs in preterm neonates. As discussed earlier, in recent years, there has been a trend to treat only selected PDAs, which are shunting significantly ${ }^{3}$. Because of the similar long-term outcomes of prophylactically treated babies, and the increased CLD and retinopathy of prematurity (ROP) in babies on medical prophylaxis, prophylactic medical management has not found much favour ${ }^{13}$. In resource-limited settings however, the tendency of favouring medical prophylactic management, especially for babies $<1000 \mathrm{~g}$, has been reported ${ }^{14}$. Moreover, unlike earlier studies, recent literature has conflicting results about the benefits of early versus late symptomatic treatment in the $<1000 \mathrm{~g}$ babies ${ }^{9}$. Currently, the timing of treatment depends on echo support. At present, we do not have much information about accurate timing of medical prophylactic or therapeutic approach in the absence of echo support. What we do know is that by the time of picking up PDA clinically, the damage due to HsPDA has already been caused ${ }^{7}$. Recently, a staging system based on score assignment to clinical situation has been described to be useful in triaging and prioritizing PDA treatment by McNamara PJ, et $a l^{3}$. The rationale of this approach was based on the current understanding that rather than being causal, there is a coincidental association of PDA with other neonatal morbidities. PDA is now being viewed as a spectrum of manifestations, and as such, only the extreme cases should be treated. This entails viewing the babies' condition from a holistic point of view. This is of vital importance in all those countries facing huge loads of neonatal morbidities.

Thus, in short, whom to treat and when to treat are the two most difficult questions to answer in all NICUs without echo support. At present, increasing the echo support seems to be the only answer, which is not easily implementable due to financial and other constraints.

\section{How to treat?}

Both medical and surgical methods are used for PDA closure. Medical management is the primary approach, surgical being reserved for failed medical treatment. Among medical methods, indomethacin and ibuprofen are well established now with the latter being better tolerated in oral form ${ }^{5}$. Recently, paracetamol, an agent which also decreases prostaglandin production by a different mechanism, has been studied. There is evidence now, that it is equally efficacious with much better safety profile than the other two agents ${ }^{6}$. In a recent study from India, oral paracetamol was found to be equally efficacious as indomethacin along with benefits of being easily available, inexpensive and having a safe short-term profile ${ }^{15}$. However, there are still some concerns about long-term neuro-developmental effects of neonatal and prenatal use of paracetamol $^{6,15}$.

Because of the underlying pathophysiology, fluid restriction and use of diuretics are counterproductive as they decrease the systemic circulatory flow. Additionally, furosemide causes prostaglandin increase, which favours persistent patency of the $\operatorname{ductus}^{15,17}$.

Surgical ligation, at present, is reserved for medically contraindicated and medically untreatable cases. World over, a decline has been noticed in surgically treated PDAs ${ }^{3.7}$. This decline can be explained by 1) PDA treatment is required in very few cases and 2) medical treatment is successful in the vast majority of cases.

\section{Biochemical markers of PDA}

Biological substances, collectively known as biomarkers, are emerging as diagnostic and prognostic markers especially in the setting of heart failure or ischaemic injury. One such marker emerging in the diagnosis of HsPDA is brain natriuretic peptide (BNP). These peptides are hormone-like molecules, produced either by atrial muscle (atrial natriuretic peptide/ANP) or by ventricular chamber wall (BNP) in response to myocardial dilatation or hypertrophy or ischaemic stress. They result in sodium and water loss, arterial relaxation and inhibition of the renin-angiotensin system. These biomarkers of cardiac origin, secreted on stretching/stressing of cardiac muscle, can be of significant value when echo assessment is not available or feasible. In a meta-analysis of studies on these markers, authors found them to have good sensitivity and specificity. However, studies in this meta-analysis had a lot of heterogeneity about inclusion and exclusion criteria, definition of HsPDA etc. ${ }^{4}$. At present, they are still a matter of 
research in PDA management. In poor-resource countries, where echo facilities are not available for NICUs in a lot of centres, these markers may be of great use in patient selection and timing of PDA management. More studies need to be done on this aspect as it may help us in patient selection even in the absence of echo.

\section{Dilemmas of PDA management in a resource- poor environment}

Although, there are a number of centres now equipped with facilities like echo, still, a large section of the preterm neonatal population is cared for in not so advanced hospitals. Due to this, the options of treating PDA are limited. As the clinician manages a new-born in the absence of echo support, the options are 1) classical clinically guided treatment and/or 2) prophylactic treatment in highrisk patients. Regarding both approaches, the evidence for efficacy is limited and as at present, it is difficult to justify both in practice ${ }^{14}$. Conventional practice has been to use clinical picture guided management i.e. to treat the baby in the clinically evident cases (tachycardia, wide pulse pressure and murmur) or symptomatically suspected situations (increased ventilator settings, cardiomegaly, pulmonary oedema etc.). However, as already discussed, the frank clinical picture of PDA appears only after the PDA has progressed way beyond the haemodynamically significant stage ${ }^{7,18}$. There is a paucity of literature on the prophylactic approach in resource limited situations. Indomethacin and ibuprofen given prophylactically have been shown to limit the short-term complications. In a recent review of early medical management of HsPDA, authors concluded that it was not associated with any benefits in terms of mortality. It further recommended more studies of early targeted treatment in $<28$ weeks babies, who are at most risk due to HsPDA, rather than more mature babies ${ }^{19}$. However, associated side-effects of these agents and apparent lack of benefit in the long-term (up to 18 months of age) further limits their usage in this way. Real long-term studies running up to late childhood (when more detailed differences in neurodevelopment and behaviour studies can be elicited) are lacking ${ }^{7}$.

Today, when the need for PDA closure is being revisited in the Western world, the neonatologist of a poor country is faced with a situation of limited options as discussed above. It is known that there is a natural reluctance to apply the principle of 'not treating PDA at all', even in Western NICUs, given its doubtful association with increased morbidity and mortality in the available literature ${ }^{3}$. That clinical approach, which lags behind in detecting and managing significant ductal shunts ${ }^{7}$, gives us immense scope to study the medical prophylactic management (with possible use of biomarkers). If medical management for prophylactic closure proves efficacious as well as safe, both in the short and long-term, it will go a long way to solving the present dilemma of managing PDA in underresourced situations. It is thus imperative to conduct large studies for pharmacologic prophylactic treatment of PDA. Alternatively, using clinical and biochemical evidence, a score based symptomatic approach can also be studied (compared to the gold standard of echo). At present, and at best, we may be able to apply the treatment approach as in Western countries, only in NICUs equipped with echo.

\section{Challenges ahead}

The quality of neonatal care varies to a large extent in many developing nations. Since PDA is a commonly diagnosed entity and most NICUs are not having echo support, many physicians rely on clinical signs alone. As discussed earlier, it is very difficult to assign the exact role of PDA in the causation of multi-factorial illnesses like NEC, CLD etc., even in advanced centres of the West ${ }^{3,11}$. Because of the heterogeneity of neonatal care in developing nations, it is very difficult to scientifically evaluate the exact need for managing PDAs. With the ease of giving oral drugs like paracetamol, which are safe in the short-term for neonates, there is apparently no hindrance in administering the drugs for both prophylactic and therapeutic usage. However, at present we do not have much information to support this approach. Keeping in mind the possibility of causing damage in a duct-dependent cardiac lesion, a clinical approach (without echo support) with clinical monitoring of four limb saturations need large comparative studies (which are echo guided) for sorting out its safety and efficacy issues. A sizable fraction of newborns also suffer from intra-uterine growth retardation. It has been reported that growth retarded babies adapt more negatively to $\mathrm{PDA}^{20}$. Thus, we cannot generalize the findings of earlier studies where this aspect has not been elaborated. Large multi-centre studies need to be carried out to answer this problem. We also need criteria for medical management of PDA in centres without echo support. Since we now know that most medical management is unwarranted and questions like who needs to be treated, when and how, have to be answered keeping these practical aspects in mind. It is apparent that as far as possible, PDA management has to be a focused and individualized approach. It is also time to evaluate the biochemical markers associated with PDA and possibly use them as indicators to start treatment ${ }^{7,12}$. A score based staging approach using the clinical picture (unrelenting ventilator settings, increased need of oxygen etc), surrogate biochemical markers, with and without echo support, can show us the way 
forward for managing PDA rationally in both resourceful and resource-limited settings $\mathrm{s}^{3,7,18}$.

\section{Conclusions}

It is important to manage PDA effectively in preterm babies (especially $<1000 \mathrm{~g}$ ) to reduce acute neonatal morbidities and improve long-term outcomes. Whom to treat and how to treat, especially in resource poor NICU centres, is a big challenge for neonatologists of the developing world. While it is prudent that a cheap, safe (both short-term and longterm), pharmacotherapy agent is needed, it should be a targeted, focused approach. We need large comparative studies in NICU environments with and without echo support, with simultaneous study of biomarkers, for finding the best strategy of managing PDA, prophylactically as well as therapeutically. We need to train more neonatologists in cardiac echo and create financial support for such facilities, at least in all teaching hospitals. While using any agent, in the absence of echo, it is of utmost importance to have a monitoring policy so as not to cause any harm to a baby with a duct-dependent cardiac lesion. Only with an increase in information by doing more studies, in poor-resource environments, on various issues as discussed above, will we be able to eliminate the dilemmas of underprivileged neonatologists of developing countries in PDA management.

\section{References}

1. Chiruvolu A, Punjwani P, Ramaciotti C. Clinical and echocardiographic diagnosis of patent ductus arteriosus in premature neonates. Early Human Development 2009; 85(3): 147-9.

https://doi.org/10.1016/j.earlhumdev.2008. 12.008

PMid: 19217224

2. El-Khuffash A, Weisz DE, McNamara PJ. Reflections of the changes in patent ductus arteriosus management during the last 10 years. Archives of Disease in Childhood Fetal and Neonatal Edition 2016; 101: F474-8.

https://doi.org/10.1136/archdischild-2014306214

PMid: 27118761

3. McNamara PJ, Sehgal A. Towards rational management of the patent ductus arteriosus: the need for disease staging. Archives of Disease in Childhood Fetal and Neonatal Edition 2007; 92: F424-F427. https://doi.org/10.1136/adc.2007.118117 PMid: 17951547 PMCid: PMC2675381
4. Kulkarni M, Gokulakrisnan G, Price J, Fernandes CJ, Leeflang M, Pammi M. Diagnosing significant PDA Using natriuretic peptides in preterm neonates: a systematic review. Pediatrics 2015; 135(2): e510-e525.

https://doi.org/10.1542/peds.2014-1995

PMid: 25601976

5. Ohlsson A, Walia R, Shah SS. Ibuprofen for the treatment of patent ductus arteriosus in preterm or low birth weight (or both) infants. Cochrane Database Systematic Review 2015; 2(2): CD003481.

https://doi.org/10.1002/14651858.CD0034 81.pub6

PMid: 25692606

6. Ohlsson A, Shah PS. Paracetamol (acetaminophen) for patent ductus arteriosus in preterm or low-birth-weight infants. Cochrane Database Systematic Review 2015; 3(3): CD010061. https://doi.org/10.1002/14651858.CD0100 61.pub2

PMid: 25758061

7. Prescott S, Keim-Malpass J. Patent ductus arteriosus in the preterm infant: Diagnostic and treatment options. Advances in Neonatal Care 2017; 17(1):10-8. https://doi.org/10.1097/ANC.0000000000 000340

PMid: 27740976

8. Fowlie PW, Davis PG. Prophylactic intravenous indomethacin for preventing mortality and morbidity in preterm infants. Cochrane Database Systematic Review 2002; 3: CD000174.

https://doi.org/10.1002/14651858.CD0001 74

PMCid: PMC1122025

9. Kaempf JW, Wu YX, Kaempf AJ, Kaempf AM, Wang L, Grunkemeier G. What happens when the patent ductus arteriosus is treated less aggressively in very low birth weight infants? Journal of Perinatology 2012; 32(5): 344-8.

https://doi.org/10.1038/jp.2011.102

PMid: 21818064

10. Nemerofsky SL, Parravicini E, Bateman D, Kleinman C, Polin RA, Lorenz JM. The ductus arteriosus rarely requires treatment in infants $>1000 \mathrm{~g}$. American Journal of Perinatology 2008; 25(10): 661-6. https://doi.org/10.1055/s-0028-1090594 PMid: 18850514 
11. Clyman RI, Couto J, Murphy GM. Patent ductus arteriosus: Are current neonatal treatment options better or worse than no treatment at all? Seminars in Perinatology 2012; 36(2): 123-9.

https://doi.org/10.1053/j.semperi.2011.09. 022

PMid: 22414883 PMCid: PMC3305915

12. Sasi A, Deorari A. Patent ductus arteriosus in preterm infants. Indian Pediatrics 2011; 48(4): 301-8.

https://doi.org/10.1007/s13312-011-00625

PMid: 21532100

13. Benitz WE. Treatment of persistent patent ductus arteriosus in preterm infants: Time to accept the null hypothesis. Journal of Perinatology 2010; 30: 241-52. https://doi.org/10.1038/jp.2010.3 PMid: 20182439

14. Heuchan AM, Clyman RI. Managing the patent ductus arteriosus: Current treatment options. Archives of Disease in Childhood Fetal and Neonatal Edition 2014; 99:F431F436. https://doi.org/10.1136/archdischild-2014306176

PMid: 24903455

15. Dash SK, Kabra NS, Avasthi BS, Sharma SR, Padhi P, Ahmed J. Enteral paracetamol or intravenous indomethacin for closure of patent ductus arteriosus in preterm neonates: A randomized controlled trial. Indian Pediatrics 2015; 52(7): 573-8. https://doi.org/10.1007/s13312-015-0677-

Z

PMid: 26244949

16. Bell EF, Acarregui MJ. Restricted versus liberal water intake for preventing morbidity and mortality in preterm infants. Cochrane Database Systematic Review 2014; 12(12): CD000503.

https://doi.org/10.1002/14651858.CD0005

03.pub3

PMid: 25473815 PMCid: PMC7038715
17. Green TP, Thompson TR, Johnson De, Lock JE. Furosemide promotes patent ductus arteriosus in premature infants with respiratory distress syndrome. New England Journal of Medicine 1983; 308: 743-8

https://doi.org/10.1056/NEJM1983033130 81303

PMid: 6828120

18. Patent ductus arteriosus in preterm neonates. AIIMS protocols in neonatology. [internet] Available at.

https://www.newbornwhocc.org/2014 pdf /Patent $\% 20$ ductus\%20arteriosus $\% 202014$. pdf. Accessed on $30^{\text {th }}$ October 2020.

19. Mitra S, Scrivens A, Kursell AM, Disher T. Early treatment versus expectant management of hemodynamically significant patent ductus arteriosus for preterm infants. Cochrane Database of Systematic Reviews 2020; 12: CD013278. https://doi.org/10.1002/14651858.CD0132 78.pub2

PMid: 33301630

20. Razak T, Magnenant E, Klosowski S, Tourneux P, Bachiri A, Storme L. Early haemodynamic consequences of patent ductus arteriosus in preterm infants with intrauterine growth restriction. Journal of Pediatrics 2007; 151: 624-8. https://doi.org/10.1016/j.jpeds.2007.04.05 8 PMid: 18035142 